polar exploration 1882-83; but no one has ever been able to make out a rational account of the behaviour of cyclonic depressions. The Norwegian school has traced with marked success the influence of the movement of the different kinds of air of which they are composed, but the origin of the currents of which they are composed is not yet understood. Disappointed, the council turned its attention to harmonic analysis of hourly values as a method of discovering the latent causes of weather, and Galton transferred his interest to eugenics.

All this while, Buys Ballot's law that wind is along the isobars with a deviation towards the low pressure and dependent for its strength upon the closeness of the isobars was recognised, and when the phenomena of turbulent motion were explained, it became apparent that the surface-layer was so much affected by turbulence that regularity in the relation of pressure to the surface-wind was not to be expected. But observation showed that in the upper air it might be assumed that the effect of turbulence is negligible, and the geostrophic relation between pressure-gradient and horizontal wind under the influence of the earth's rotation might be regarded as a definite meteorological law, most definite where isobars are straight and parallel. Moreover, it accounts for the development of high pressure, a matter which has been neglected in the study of weather. Wherever the horizontal wind in an air-current is not in agreement with the formula the rotation of the earth will push it sideways, from high to low if the horizontal component is too slow, from low to high if it is too fast. The adjustment will always be operative over the whole mass of the moving air so that the air may be regarded as adjusting the gradient to its motion as a bicyclist adjusts his inclination to the vertical.

In the concentration of attention on the closed isobars of cyclones and anticyclones the study of the straight isobars between them has been overlooked; and it may fairly be asserted that if the origin of the currents with straight isobars can be traced, they may be relied upon to adjust the pressure-gradient to meet the exigencies of the wind in the upper air, which is an indubitable expression of actual energy of vast amount.

Meanwhile, the air is everywhere stratified according to its entropy, and any change in the entropy by gain or loss of heat, by conduction to or from the ground, by radiation to or from the air, or by the condensation or evaporation of water within its mass, will have its effect on the stratification, and the readjustment of the stratification will transform the thermal energy of the air into the actual energy of wind. The currents of straight isobars have, therefore, an obvious claim upon the students of the dynamics of the atmosphere. The extension of the area of the daily map to include the whole hemisphere makes productive investigation possible.

To summarise, our survey leads to the conclusion that meteorology has been mistaken in regarding the cyclonic depression and the anticyclone of a hypothetical sea-level map as the principal agents in control of the energy of weather, and asks for the consideration of the currents in the free air indicated by straight isobars as expressing the real estate of energy in the atmosphere, while the differences in the distribution of entropy and water-vapour associated therewith represent its potential estate.

\title{
Recent Developments in Optical Glass Manufacture.*
}

\section{By W. M. Hampton and W. N. Wheat.}

$\mathrm{T}^{\mathrm{H}}$ HE demand for particular types of optical glass has changed considerably during the postWar period, largely under the influence of the remarkable development of the modern photographic lens, which has been based on the production of the more extreme types of glass, notably the barium crowns.

This change is shown by the following table of the percentage of the various broad types manufactured by Messrs. Chance Brothers and Co., Ltd., of Birmingham, in the years 1914, 1918, 1929.

\begin{tabular}{|c|c|c|c|}
\hline & 1914. & 1918. & 1929. \\
\hline Hard Crown and Zine Crown & 24 & 29 & 7 \\
\hline Borosilicate Crown & 23 & 14 & 18 \\
\hline Flint & 27 & 14 & 11 \\
\hline Dense Flint & 23 & 27 & 13 \\
\hline Extra Dense Flint & 2 & 4 & 16 \\
\hline Barium Crowns & 1 & 12 & 35 \\
\hline
\end{tabular}

Recent research has enabled the manufacture of the barium glasses to be put on a routine basis, the

* Substance of a paper read at the Science Museum, South Kensington, on Oct. 29, in connexion with the Exhibition of Modern Technica and Artistic Glasses. variation in optical constants from one melt to another not being appreciably greater than is normally obtained with the simpler types. This is largely due to the utilisation of refractories for the melting-pots of a composition which is sufficiently resistant to the solvent action of these very corrosive glasses, thus minimising the trouble, once serious, of dilution by aluminous material dissolved from the pot wall. Improvements in the knowledge of melting technique and of the volatilisation losses which accompany the process of fusion have enabled a more strict control to be exercised over the types of barium glasses which contain a percentage of boric oxide in place of silica, these glasses being indispensable in the manufacture of the modern wide aperture photographic lens. The most extreme example in this series has a refractive index of 1.6140 and a value of $V$, or reciprocal dispersive power of $59 \cdot 8$, representing the practical limit to which it has so far been found possible to go.

A knowledge of volatilisation losses is of great importance if exact control of the melting of the flint glasses is to be maintained, and it has been established that, within the limits of composition 
obtained in most optical glasses, the losses of any given oxide may be taken as being directly proportional to the concentration of that oxide, this proportionality holding in the case of lead oxide up to about 50 per cent concentration of $\mathrm{PbO}$. Working at $1400^{\circ} \mathrm{C}$. in a covered pot, it has been found that the loss of lead oxide may be expressed as $0.014 \mathrm{lb}$. per $100 \mathrm{lb}$. of glass for every one per cent of the oxide present, the corresponding figure for $\mathrm{K}_{2} \mathrm{O}$ being 0.12 . These values, of course, presuppose constancy in temperature, shape of pot, and length of melting-time.

It is easily seen from the above considerations that in the case of an extra dense flint glass, approximately represented by $\mathrm{SiO}_{2}, 44$ per cent, $\mathrm{PbO}$, 50 per cent, and $\mathrm{K}_{2} \mathrm{O}, 6$ per cent, the loss in pounds of $\mathrm{K}_{2} \mathrm{O}$ may exceed the total loss of $\mathrm{PbO}$ and the glass after melting actually be richer in $\mathrm{PbO}$ than is calculated from the batch composition.

With our present methods of manufacture, perfectly isotropic glasses are probably an impossibility. The degree of homogeneity obtained by stirring is the result of a compromise between various opposing factors. Thus the action of stirring, as the pot and the material of the stirrer itself are very slightly soluble in the glass, will tend to produce veins of different refractive index faster than they can be eliminated by the mixing process if the temperature of the melt is too high, this being due to the rapid increase of the rate of chemical attack with rising temperature. If volatile constituents are present a high temperature of stirring may mean that the surface of the glass, slightly poorer than the rest in the volatile oxide, may be stirred in faster than the resulting veins can be eliminated. On the other hand, too low a temperature produces a heavy 'drag', which may draw in aluminous material from the pot wall in sufficient quantity to render the melting useless.

The most noteworthy recent advance in optical glass manufacture is the production of improved refractories for pots. This work was undertaken recently by Messrs. Chance Brothers and Co., Ltd., with the co-operation of Sir Herbert Jackson, and full-scale pots based on the experimental smallscale samples have been in use for some time. It has been found that the more acidic glasses, such as the ordinary crowns and especially the borosilicates, are best melted in pots having a relatively acidic clay composition- $-\mathrm{Al}_{2} \mathrm{O}_{3}, 5 \mathrm{SiO}_{2}$ being typical. The more basic glasses, such as the flints and the barium crowns, need a lower concentration of silica in the pot material ; in these cases a reduction up to 10 per cent of $\mathrm{SiO}_{2}$ may be made. One of the immediate advantages gained from the use of these new pots was an improvement in the transparency to light of the resulting glasses. The task of measuring the small differences in absorption which exist between various meltings of optical glass is a difficult one, and the figures given in the present paper were obtained by the British Scientific Instrument Research Association, using an apparatus similar to that described by W. D. Haigh. ${ }^{1}$

It has been found that if the absorption per inch of glass material at each wave-length is plotted against percentage of iron oxide present in the glass, the points lie on smooth curves which do not pass through the origin but indicate a definite absorption at zero concentration of iron. However, the absorption in optical glass is largely proportional to the amount of iron oxide present, and the new refractories, coupled with the use of only the purest raw materials, have enabled this to be reduced to a minimum.

The extent of the improvement is shown by the following figures, which are published by permission of Sir Herbert Jackson :

\begin{tabular}{|c|r|r|r|r|r|r|r|r|}
\hline Melt. & $\begin{array}{l}\text { Iron } \\
\text { per } \\
10^{6} .\end{array}$ & \multicolumn{2}{l|}{ Percentage of Light extinguished per Inch of Glass. } \\
\hline B.S.C. 5358 & 180 & $12 \cdot 50$ & $3 \cdot 70$ & $4 \cdot 62$ & $3 \cdot 10$ & $2 \cdot 76$ & $2 \cdot 88$ & $4 \cdot 10$ \\
B.S.C. 6029 & 50 & 2.94 & 0.82 & 1.50 & $1 \cdot 10$ & $0 \cdot 76$ & $0 \cdot 91$ & $1 \cdot 73$ \\
\hline
\end{tabular}

A similar improvement has been made in most of the optical glass types, particularly the dense flints, the barium crowns, and very heavy lead glasses of ${ }^{n} D$ up to 1.8 ; and it is now safely claimed that the optical glasses of the new high transparency type made in Great Britain have a lower absorption of light than any glass of foreign manufacture.

In the efforts to eliminate iron oxide from the glass, work has been done on the purification of sand, and a process has been worked out and patented, ${ }^{2}$ using a reducing gas such as sulphur dioxide and chlorine, which has on an experimental scale enabled the iron oxide concentration to be reduced from 0.008 to 0.0025 per cent. The use of purified sands may enable further improvements in transparency to be made in the near future, the present values being considered the maximum possible with existing raw materials.

Although from time to time it has been suggested that the chilling which takes place in moulding may

\begin{tabular}{|c|c|c|c|}
\hline Type. & $\begin{array}{l}\text { Refractive } \\
\text { Index and } \\
\text { Value of } V .\end{array}$ & $\begin{array}{l}\text { Autoclave Test } \\
\text { (4 Atmospheres). }\end{array}$ & $\begin{array}{l}\text { Test using Steam. } \\
\text { Steam under } \\
\text { Atmospheric } \\
\text { Pressure. }\end{array}$ \\
\hline B.S.C. & $\begin{array}{l}1 \cdot 5090 \\
64 \cdot 3\end{array}$ & Unattacked & Unattacked. \\
\hline H.C. & $\begin{array}{l}1 \cdot 5159 \\
60 \cdot 3\end{array}$ & $\begin{array}{l}\text { Practically } \\
\text { unaffected }\end{array}$ & Unattacked. \\
\hline L.F. & $\begin{array}{l}1 \cdot 5475 \\
45 \cdot 3\end{array}$ & $\begin{array}{l}\text { Slightly } \\
\text { affected }\end{array}$ & $\begin{array}{l}\text { Slightly } \\
\text { affected } \\
\text { (wipes } \\
\text { clean). }\end{array}$ \\
\hline Soft Crown & $\begin{array}{l}1 \cdot 5143 \\
56 \cdot 8\end{array}$ & $\begin{array}{l}\text { Marked film- } \\
\text { ing }\end{array}$ & Unaffected. \\
\hline E.L.F. & $\begin{array}{l}1 \cdot 5337 \\
49 \cdot 1\end{array}$ & $\begin{array}{l}\text { Badly } \\
\text { attacked }\end{array}$ & $\begin{array}{l}\text { Surface dulled } \\
\text { but wipes } \\
\text { clean. }\end{array}$ \\
\hline D.B.C. & $\begin{array}{l}1 \cdot 6140 \\
56 \cdot 2\end{array}$ & $\begin{array}{l}\text { Slightly } \\
\text { affected }\end{array}$ & $\begin{array}{l}\text { Severe irides- } \\
\text { cent tarn- } \\
\text { ish. }\end{array}$ \\
\hline D.B.C. & $\begin{array}{l}1 \cdot 6140 \\
59 \cdot 4\end{array}$ & $\begin{array}{l}\text { Slightly } \\
\text { affected }\end{array}$ & $\begin{array}{l}\text { Completely } \\
\text { dulled. }\end{array}$ \\
\hline
\end{tabular}

cause heterogeneity in optical glass which is not removed by the subsequent annealing, no direct evidence in support of this has yet been advanced, and it is still considered that the laws approximately represented by Twyman's equation are the only considerations which govern the degree of freedom 
from strain of a block after a certain heat treatment. The essential condition is the accurate measurement of the upper temperature at which strain in the glass block is released in a reasonably short space of time.

Research on methods of testing the resistance of polished glass surfaces to atmospheric attack has led to the abandonment of the old autoclave test of superheated steam at four atmospheres pressure. The abnormality of the conditions of this test must make the results open to doubt, and it has been found that the modified method of testing in watervapour at atmospheric pressure and a temperature of $80^{\circ} \mathrm{C}$. gives results more in accordance with general experience, although the period of the test has to be increased from two hours to two weeks. The revised method of testing puts the various types of optical glass in a different order as regards resistance to surface attack, some of the types previously thought unstable from the results of the autoclave test now being shown to be perfectly reliable, while certain other types previously thought of fair durability are now shown to be very unstable, confirming the experience of the lens manufacturer.

The table on p. 927 shows the classification of representative types of optical glass according to the autoclave and atmospheric durability tests.

Among the new types which have been successfully produced in recent years is a dense barium flint made of ${ }^{n} D$ 1.6437, ${ }^{n} C-{ }^{n} F \quad 0.01332, V 48 \cdot 3$, which is as extreme a member of the flint series as the barium crowns are in the crown series. The very heavy lead glasses of ${ }^{n} D$ up to 1.8 are now produced in large blocks of a degree of homogeneity and freedom from colour never previously attained, this being largely due to the use of the new refractories and correct temperature control in melting.

1 "Proceedings of the Optical Convention", 1926.

2 Brit. Pat. 325,386 (1929), Chance Brothers and Co., Ltd., and J. English.

\section{Obituary.}

Dr. S. W. Stratton.

GAMUEL WESLEY STRATTON was born at $\$$ Litchfield, Illinois, in 1861. He graduated in 1884 from the University of Illinois, where he remained for the next eight years, at first as an instructor, then as professor of mathematics, and finally as professor of physics and electrical engineering. In 1892 he became assistant professor of physics and later professor in the University of Chicago. Nine years afterwards he was invited by the Assistant Secretary of the Treasury to formulate a project for the development of work on weights and measures, and in 1901 was mainly responsible for the Act which established the Bureau of Standards at Washington. Of this he became the first director, retaining the position until 1923 , when he was appointed president of the Massachusetts Institute of Technology. He had a lifelong connexion with the American Navy, and in 1898 served during the Spanish American War. This brief summary of his activities shows that the most important part of his work was connected with the Bureau of Standards, which is indebted to him for its existence and for many of its most striking developments.

Stratton was a welcome visitor to the National Physical Laboratory, and spent some time at Bushy House in early years; from this time on the connexion between the two institutions has been a close one. Visitors to the National Physical Laboratory will remember an old chestnut tree near the door of Bushy House, said on good authority to have been planted by Charles II. Round the Bureau of Standards, when founded, was a wood of chestnuts ; the site was part of Washington's estate, and tradition says that, after one of his visits to England, Washington took back the chestnuts which formed the nucleus of this wood.

An Electrical Congress, in connexion with an International Exhibition, took place at St. Louis in 1904 and proved to be Stratton's introduction to that international work which for the rest of his life occupied much of his time. This Congress passed two important resolutions: one in favour of a formal International Conference to deal with electrical units, the other inviting the leading technical societies of the world to co-operate in the standardisation of electrical machinery; the first led to the International Conference on Electrical Units in London in 1908, the second to the establishment of the International Electrotechnical Commission.

After the St. Louis Conference, at which I represented the British Government, I spent some time with Stratton at Washington discussing with him, much to my own profit, questions of laboratory organisation suitable for any institute such as those we directed respectively. In 1905 he became a member of the International Committee of Weights and Measures and, as a result, a frequent visitor to this side of the Atlantic

The International Electrical Conference foreshadowed at St. Louis was summoned by the British Government and met in the rooms of the Royal Society in October 1908. Stratton was prominent among the American delegates; he was accompanied by Dr. E. B. Rosa, who had done much valuable work at the Bureau on electrical units.

A distinction had been drawn at the Chicago Electrical Congress, some years previously, between the ohm, the ampere, and the volt, multiples of the C.G.S. units, and the International Ohm, Ampere, and Volt taken to be close approximations to the absolute units, and defined in a manner which it was hoped would permit their realisation with sufficient accuracy for all practical purposes in any fully equipped laboratory. Some of the American delegates would have preferred definitions based only on the C.G.S. units.

The Conference also passed a resolution recommending the various governments interested to establish a permanent International Commission for Electrical Standards and, pending the appointment of this, requested its president, Lord Ray-

$$
\text { No. } 3240 \text {, VoL. 128] }
$$

